\title{
Long-term Estradiol-17 $\beta$ Administration Decreases the Number of Neurons in the Caudal Mesenteric Ganglion Innervating the Ovary in Sexually Mature Gilts
}

\author{
Marlena KOSZYKOWSKA ${ }^{1)}$, Jaroslaw CAkKA ${ }^{2)}$, Piotr SZWAJCA ${ }^{2)}$ and Barbara JANA ${ }^{1)}$
}

1) Division of Reproductive Endocrinology and Pathophysiology, Institute of Animal Reproduction and Food Research of the Polish Academy of Sciences, Olsztyn 10-747 and ${ }^{2)}$ Division of Clinical Physiology, Department of Functional Morphology, Faculty of Veterinary Medicine, University of Warmia and Mazury, Olsztyn 10-718, Poland

\begin{abstract}
The effect of estradiol- $17 \beta\left(\mathrm{E}_{2}\right)$ on the number and distribution of neurons in the caudal mesenteric ganglion (CaMG) supplying the ovary of adult pigs was investigated. Also, the numbers of ovarian dopamine- $\beta$-hydroxylase $(\mathrm{D} \beta \mathrm{H}-)$, neuropeptide Y (NPY-), somatostatin (SOM-), galanin (GAL-) and estrogen receptor (ER)-immunoreactive perikarya as well as the density of the intraganglionic nerve fibers containing D $\beta \mathrm{H}$ and/or NPY, SOM, GAL were determined. $\mathrm{E}_{2}$ was administered i.m. from day 4 of the first studied estrous cycle to the expected day 20 of the second studied cycle. Injections of $E_{2}(1)$ increased the $E_{2}$ level in the peripheral blood approximately $4-5$ fold, $(2)$ decreased the number of small-sized Fast Blue-positive postganglionic neurons in the CaMG, (3) decreased the number of small perikarya in the ventral, dorsal and central regions of the CaMG, (4) decreased the number of large perikarya in the dorsal and central regions, (5) decreased the number of small and large perikarya in the CaMG that were $\mathrm{D} \beta \mathrm{H}^{+} / \mathrm{NPY}^{+}$, (6) decreased the number of small $\mathrm{D} \beta \mathrm{H}^{+}$but NPY- perikarya, (7) decreased the number of small perikarya coded $\mathrm{D} \beta \mathrm{H}^{+} / \mathrm{SOM}^{+}$and $\mathrm{D} \beta \mathrm{H}^{+} / \mathrm{SOM}^{-}$, (8) decreased the number of small $\mathrm{D} \beta \mathrm{H}^{+} / \mathrm{GAL}^{-}$perikarya, (9) decreased the number of small and large perikarya expressing ER subtypes $\alpha$ and $\beta$ and (10) decreased the total number of nerve fibers in the CaMG containing $\mathrm{D} \beta \mathrm{H}$ and/or NPY and $\mathrm{D} \beta \mathrm{H}$ and/or GAL. These results show that long-term $\mathrm{E}_{2}$ treatment of adult gilts downregulates the populations of both noradrenergic and ERs expressing ovarian neurons in the CaMG. Our findings suggest also that elevated $E_{2}$ levels that occur during pathological states may regulate gonadal function(s) by affecting ovary supplying neurons.
\end{abstract}

Key words: Caudal mesenteric ganglion, Estradiol-17 $\beta$, Ovarian neuron, Pig

(J. Reprod. Dev. 57: 62-71, 2011)

I n pigs, the caudal mesenteric ganglion (CaMG) is virtually the sole source of sympathetic prevertebral neuronal input to the neural circuits controlling the large intestine [1, 2], ovary [3, 4], oviduct [5] and uterus [6]. Virtually all ovary-projecting postganglionic CaMG neurons in immature and adult pigs are noradrenergic; that is, they express enzymes participating in the synthesis of noradrenaline-tyrosine hydroxylase (TH) and dopamine- $\beta$-hydroxylase $(\mathrm{D} \beta \mathrm{H})[3,4]$. Moreover, sympathetic perikarya and nerve fibers within this ganglion have also been found to be immunoreactive to other active substances in a number of mammals, including adult cats [7], immature rats [8], fetal and adult guinea-pigs [9] and prepubertal pigs [3, 4]. The reactive substances include neuropeptide Y (NPY), somatostatin (SOM), galanin (GAL), calcitonin gene-related peptide (CGRP), cholecystokinin, bombesin/gastrin-releasing peptide, substance P (SP), vasoactive intestinal polypeptide (VIP), opioid peptides and enkephalins. The abundance of bioactive substances expressed in postganglionic sympathetic CaMG perikarya innervating the ovary correlates with a variety of the ovarian sympathetic actions including regulation of steroidogenesis, blood supply as well as development and ovula-

Received: April 16, 2010

Accepted: August 18, 2010

Published online in J-STAGE: September 24, 2010

(C)2011 by the Society for Reproduction and Development

B Jana (e-mail: b.jana@pan.olsztyn.pl.) tion of follicles (as reviewed by Kotwica et al. [10] and Jana et al. [11]).

In rats, a close relationship was found between estrogens and sympathetic and sensory neurons supplying the genitourinary system. Estrogen receptor (ER) subtypes $\alpha$ and $\beta$ are localized in preand paravertebral (at thoracolumbar neuromeres) sympathetic neurons projecting to the ovary and uterus $[12,13]$ and proximal urethra [14]. The number of celiac ganglion neurons innervating the rat ovary and the content of ERs in these cells decreased after prenatal diethylstilbestrol exposure [15]. In turn, prepubertal $\beta$ estradiol-17-cypionate treatment increased the neuronal size in the rat celiac ganglion [12]. In female rats, DRG sensory neurons in $\mathrm{L}_{6}-\mathrm{S}_{1}$ segments that innervate the uterus $[16,17]$ and urinary bladder [18] also express ER subtypes $\alpha$ and $\beta$. In rats, an increase in the content of ER $\alpha$ in $\mathrm{L}_{6}-\mathrm{S}_{1} \mathrm{DRG}$ neurons projecting to the uterine cervix near term is thought to occur in parallel with augmentation of plasma estrogens. The expressions of ERs, SP [19], CGRP [20] and pituitary adenylate cyclase-activating polypeptide (PACAP) [21] in these ganglia may be important for cervical ripening and consequently for initiation of the birth process. Moreover, estradiol-17 $\beta\left(\mathrm{E}_{2}\right)$ dose-dependently increased the synthesis of the above-mentioned peptides in the DRGs of ovariectomized rats [1921]. In addition, long-term treatment with $\mathrm{E}_{2}$ downregulated the expression of $\beta$-preprotachykinin mRNA encoding SP in the DRG [22]. 
Many pathological processes occurring in the ovaries and other organs (e.g., pituitary and uterus) of both women and animal females may cause significant disturbances in the steroidogenic activity of the ovaries, resulting in changes in the patterns of circulating steroid hormones. Ovarian follicular cysts cause marked increases in the $\mathrm{E}_{2}$ and/or estrone concentrations in blood plasma in cows [23-25] and pigs [26, 27]. Hyperestrogenism is also caused by ovarian tumors such as folliculoma and thecoma [28]. In addition, many foods contain xenoestrogens, such us pesticides, mycotoxins (zearalenone and its derivatives) and phytoestrogens (substances naturally occurring in plants), acting mainly via ERs to disturb many endocrine functions and reproductive processes [29]. Although neuroendocrine interactions have been studied in rodents, there is lack of data concerning the effect of sex steroids on the peripheral nervous system of females of domestic animals. In fact, the pig, due to its embryological, anatomical and physiological similarities to humans, constitutes an especially valuable species for biomedical research [30]. Based on these findings, we hypothesize that elevated levels of endogenous estrogens during pathological states (also xenoestrogens) can change the number and distribution of sympathetic ovarian neurons in the CaMG and consequently affect gonadal functions. To test this hypothesis, we examined the CaMGs of mature, cycling gilts to estimate the effect of long-term $\mathrm{E}_{2}$ administration (simulation of pathological states occurring with elevated estrogen levels) on 1) the overall number and distribution of ovarian neuronal perikarya, 2) the numbers of ovarian perikarya containing $\mathrm{D} \beta \mathrm{H}$ and/or NPY, SOM, GAL as well as ER subtypes $\alpha$ and/or $\beta$ and 3) the density of nerve fibers containing $\mathrm{D} \beta \mathrm{H}$ and/or NPY, SOM, GAL.

\section{Materials and Methods}

The experiment was performed on six female crossbred pigs (Large White $\times$ Landrace), aged 7-8 months and weighting 90-110 $\mathrm{kg}$, over the course of two controlled estrous cycles. The estrousshowing behavior was detected using a boar. Three days before surgical operations, the animals were transported from a farm to the local animal house and kept in individual stalls under natural light and temperature. They were fed a commercial grain mixture and tap water ad libitum. We followed the principles of animal care (NIH publication No. 86-23, revised in 1985), which were approved by the Local Ethics Commission for Animal Experiments (Agreement no 21/N).

On day 3 of the first studied estrous cycle (day 0 of the study), all gilts were subjected to median laparotomy under general anaesthesia induced by azaperone $(1 \mathrm{ml} / 10 \mathrm{~kg}$ of body mass, Stresnil, Janssen Pharmaceutica N.V., Belgium) and sodium pentobarbital (30 mg/1 kg of body mass, Vetbutal, Biovet, Poland) to expose the ovaries. After an abdominal incision, the right and left ovaries were gently removed from the surrounding tissues, and a 5\% solution of fluorescent retrograde neuronal tracer Fast Blue (FB; EmsChemie GmbH, Germany) was applied to each ovary. The right and left sides of the organs were injected 5 times $(10 \mu \mathrm{l}$ of the dye solution per 1 injection for a total volume of $100 \mu$ per ovary) using a Hamilton syringe equipped with a 26-gauge needle, keeping a similar distance between the places of the injections. To minimize diffusion of the tracer into surrounding tissues (e.g., bursa ovary, mesosalpinx and oviduct infundibulum), the needle was left in situ for at least 4 min after each injection, and thereafter the injection area was subsequently rinsed with isotonic saline and gently wiped with gauze. In addition, the polyvinyl cannula (outer diameter $2.2 \mathrm{~mm}$, inner diameter 1.8, Tomel Tomaszów Maz., Poland) was inserted into the jugular vein of each gilt in order to collect blood samples.

Next, the gilts were randomly assigned to one of the following two groups: the control group (group $I, n=3$ ) and experimental group (group II, $n=3$ ). In the gilts of group I, from day 4 of the first studied estrous cycle (day 1 of the study) to the expected day 20 of the second studied cycle, i.e., within 38 consecutive days, $2 \mathrm{ml}$ of oil was injected i.m. every $12 \mathrm{~h}$ (at 0700 and $1900 \mathrm{~h}$ ). In the gilts of group II, $1000 \mu \mathrm{g}$ of $\mathrm{E}_{2}$ (Sigma) in $2 \mathrm{ml}$ of corn oil was injected at the same time and in the same manner as for group I. The applied dose of $E_{2}$ was determined based on our preliminary experiment showing that its application increases the peripheral blood $\mathrm{E}_{2}$ concentration by about 4-5 fold. According to the available reports, this $E_{2}$ blood concentration accompanies pathological states, such as ovarian cysts $[24,27]$ and tumors [31]. It has also been found that estrogen application results in significant decreases in ERs peripheral sympathetic [15] and sensory [32] neurons. Moreover, for determination of the $\mathrm{E}_{2}$ level, blood samples were collected from gilts of both groups through out the whole period of $E_{2} /$ oil administration (twice a day-0900 and $2100 \mathrm{~h}$ ). Immediately afterwards, the samples were placed on ice, where they were kept until centrifugation $(1500 \times g$, at $4 \mathrm{C})$. After the last $\mathrm{E}_{2} / \mathrm{oil}$ injection, the gilts were deeply reanesthetized (following the same procedure as applied before the laparotomy) and perfused transcardially via the ascending aorta with $4 \%$ paraformaldehyde in $0.1 \mathrm{M}$ phosphate buffer (PB; $\mathrm{pH} 7.4$ ). After perfusion, the bilateral CaMGs were removed, postfixed by immersion in the same fixative for $10 \mathrm{~min}$, washed with $0.1 \mathrm{M} \mathrm{PB}(\mathrm{pH} 7.4)$ over two days and finally transferred to and stored at $4 \mathrm{C}$ in $18 \%$ buffered sucrose solution ( $\mathrm{pH}$ 7.4) containing $0.01 \%$ natrium azide $\left(\mathrm{NaN}_{3}\right)$ until further processing.

Serial $10-\mu \mathrm{m}$ cryostat sections (Frigocut, Reichert-Jung, Nussloch, Germany) of the ganglion were mounted on chrome alumcoated slides. By the use of an Olympus BX51 microscope (Olympus Polska Sp. z.o.o., Warsaw, Poland), equipped for epiillumination fluorescence microscopy (V1 module: excitation filter $330-385 \mathrm{~nm}$, barrier filter $420 \mathrm{~nm}$ ), the occurrence of retrogradely FB-labelled neurons was checked in serial sections of the bilateral ganglia. Sections with FB-labelled perikarya were processed for immunocytochemistry, applying a routine double-labelling immunofluorescence technique. After air-drying at room temperature for $45 \mathrm{~min}$ and rinsing in $0.1 \mathrm{M}$ phosphate-buffered saline (PBS; $\mathrm{pH}$ 7.4; $3 \times 10 \mathrm{~min}$ ), the sections were incubated in a blocking buffer containing 10\% normal goat serum (MP Biomedicals, Solon, $\mathrm{OH}$, USA), $0.1 \mathrm{M}$ PBS, $0.1 \%$ donkey serum (Abcam, Cambridge, UK), 1\% Triton X-100 (Sigma-Aldrich, St. Louis, MO, USA), 0.05\% Thimerosal (Sigma-Aldrich) and $0.01 \% \mathrm{NaN}_{3}$ for $1 \mathrm{~h}$ at room temperature to reduce non-specific background staining. Subsequently, after another wash in PBS $(3 \times 10 \mathrm{~min})$, the sections were incubated overnight at room temperature with primary antis- 
era raised against the $\mathrm{D} \beta \mathrm{H}$ (mouse, MAB308, Chemicon, Harrow, UK, dilution 1:1500) and/or NPY (rabbit, NA1233, Enzo Life Sciences International, Inc., Plymouth Meeting, PA, USA, dilution 1:1500), SOM (rabbit, 11180, MP Biomedicals, LLC, Solon, USA, dilution 1:1500), GAL (rabbit, T-4326, Peninsula Laboratories, San Carlos, CA, USA, dilution 1:8000). Also, the ganglional sections with FB-labelled perikarya were incubated with antisera against ER subtype $\alpha$ (polyclonal rabbit against the C-terminus of ER $\alpha$ of mouse origin, sc-542, Santa Cruz Biotechnology, Santa Cruz, CA, USA, dilution 1:1000) and antisera against ER subtype $\beta$ (monoclonal mouse against the human $\mathrm{C}$-terminus region of the $\mathrm{ER} \beta 1$ isoform, MCA1974, AbD Serotec, Raleigh, NC, USA, dilution 1:20). According to previous reports, immunocytochemical detection revealed the nuclear as well as cytoplasmatic localization of ERs in the studied tissues [12, 14, 17, 18].

Following subsequent rinsing in PBS $(3 \times 10 \mathrm{~min})$, the sections were incubated with biotynylated donkey anti-rabbit IgG (AP132B, Chemicon, Harrow, UK, dilution 1:1000) for $1 \mathrm{~h}$ at room temperature and subsequently with FITC-conjugated donkey anti-mouse IgG (715095150, Jackson ImmunoResearch Laboratories, Inc., West Grove, PA, USA, dilution 1:800) and CY3-conjugated streptavidin (016160084, Jackson ImmunoResearch Laboratories, Inc., West Grove, PA, USA, dilution 1:9000) for $1 \mathrm{~h}$ at room temperature to visualize the antibody combinations: $\mathrm{D} \beta \mathrm{H} / \mathrm{NPY}, \mathrm{D} \beta \mathrm{H} /$ $\mathrm{SOM}$ and $\mathrm{D} \beta \mathrm{H} / \mathrm{GAL}$. Next, the washed sections were coverslipped in carbonate-buffered glycerol $(\mathrm{pH} \mathrm{8.6)}$. Standard tests (preabsorption for the used antisera with the respective antigen at a concentration of 20-50 $\mu \mathrm{g}$ antigen $/ \mathrm{ml}$ diluted antiserum, omission of primary or secondary antisera and replacement by non-immune sera of all the primary antisera used) were employed to control the specificity of immunofluorescence. Specificity of the retrograde tracing was checked using various tests described previously [3].

Retrogradely labelled/double-immunostained neurons were analyzed and photographed with the appropriate filter sets for FITC (B1 module, excitation filter $450-480 \mathrm{~nm}$, barrier filter $515 \mathrm{~nm}$ ) and CY3 (G1 module excitation filter $510-550 \mathrm{~nm}$, barrier filter $590 \mathrm{~nm}$ ). All D $\beta \mathrm{H}$-, NPY-, SOM- and GAL-immunoreactive and/ or all retrogradely labelled cell bodies were counted in every fourth section of the bilateral CaMGs. Only neuronal profiles with a visible nucleus were scored to avoid double counting. The localization of perikarya was estimated for particular regions of the CaMG, according to the method described previously [3]. Briefly, the cranial region of the ganglion constitutes the area corresponding to the first lumbar splanchnic nerve and intermesenteric nerve; the dorsal region constitutes the area corresponding to the second and third splanchnic nerves; the caudal region constitutes the area corresponding to the fourth lumbar splanchnic nerve and hypogastric nerve; and finally, the ventral region constitutes the area corresponding to the caudal colonic nerves. Also, perikarya were divided into two subclasses, small $(23 \pm 10 \mu \mathrm{m}$ in diameter $)$ and large (51 $\pm 17 \mu \mathrm{m}$ in diameter) [3]. Their sizes were measured by using the Cell-F imaging software Olympus Polska Sp. z.o.o., Warsaw, Poland. Sizes of neurons were calculated by measurements of the long and short axes of the perikaryon. The average value of the diameter of the perikaryon was assigned using the equation $\mathrm{d}=\sqrt{1 \times \mathrm{k}}$, where $\mathrm{d}$ equals the diameter of a circle with a surface area that is the most similar to the surface area of an ellipsoidal figure with long axis 1 and short one $\mathrm{k}$ [33]. In addition, the intraganglionic numbers of nerve fibers containing $\mathrm{D} \beta \mathrm{H}$ and/or NPY, SOM or GAL found near ovarian perikarya were counted. Pictures were captured by a digital camera connected to a PC and analyzed with the AnalySIS software (version 3.02, Olympus Soft Imaging Solutions, Muenster, Germany).

The level of $E_{2}$ in blood plasma was measured by the radioimmunoassay procedure described by Hotchkiss et al. [34]. The antibodies (code BS/88/754) were obtained from the Department of Animal Physiology, University of Warmia and Mazury in Olsztyn, Poland, and characterized by Szafrańska et al. [35]. The sensitivity of the assay was $5 \mathrm{pg} / \mathrm{ml}$. The intra- and interassay coefficients of variation were 7.1 and $12.2 \%$, respectively.

All data concerning ganglia were calculated per one ganglion for the control and experimental groups. The mean $( \pm$ SEM) total number of perikarya and numbers of nerve fibers were compared between the groups by the Student's $t$-test. To calculate the statistical significance of the mean $( \pm$ SEM) numbers of particular neuronal sets (small, large, with different chemical coding, expressing ERs) in the ganglion, one-way analysis of variance (ANOVA) followed by the Newman-Keuls test was performed. The mean ( \pm SEM) $E_{2}$ levels were calculated for all samples taken each day for all control and $E_{2}$-treated gilts. The collected data were statistically assayed by two-factor analysis of variance (group $\times$ time) with repeated measures. The Neuman-Keuls test was applied for calculation of the statistical significance of mean differences (InStat, GraphPad, San Diego, CA, USA). Differences with a probability of $\mathrm{P}<0.05$ were considered significant.

\section{Results}

\section{Concentrations of $E_{2}$ in peripheral blood}

The mean daily $\mathrm{E}_{2}$ concentrations in the peripheral blood of the gilts receiving this hormone were higher $(\mathrm{P}<0.05-0.001$, about 4 5 -fold) on all studied days than those in the control gilts.

\section{The number and distribution of ovarian $\left(F B^{+}\right)$neurons in the CaMG}

In the experimental group, the total number of FB-positive perikarya in the CaMGs decreased $(\mathrm{P}<0.05)$ compared with the control ganglia $(95.03 \pm 49.44$ vs. $342.1 \pm 98.41$, respectively). The number of small cells in the control group was greater $(\mathrm{P}<0.01)$ than that of large ones $(262.5 \pm 79.13$ vs. $80.33 \pm 24.56$, respectively), while the proportions of the two size classes of cells in the experimental group were similar $(54.33 \pm 28.72$ and $41.1 \pm$ 21.13 , respectively). Compared with the control group, the $\mathrm{E}_{2}$ treatment led to decrease $(\mathrm{P}<0.05)$ only in the number of small perikarya ( $262.5 \pm 79.13$ vs. $54.33 \pm 28.72$, respectively), while the numbers of large perikarya did not significantly differ in both groups.

Compared with the control group, the experimental group had fewer $(\mathrm{P}<0.001)$ small cells in the ventral, dorsal and central regions (Fig. 1A). Also, the numbers of large cells in the dorsal $(\mathrm{P}<0.05)$ and central $(\mathrm{P}<0.001)$ areas of the CaMGs in the experimental group were lower than those in the control ganglia (Fig. 

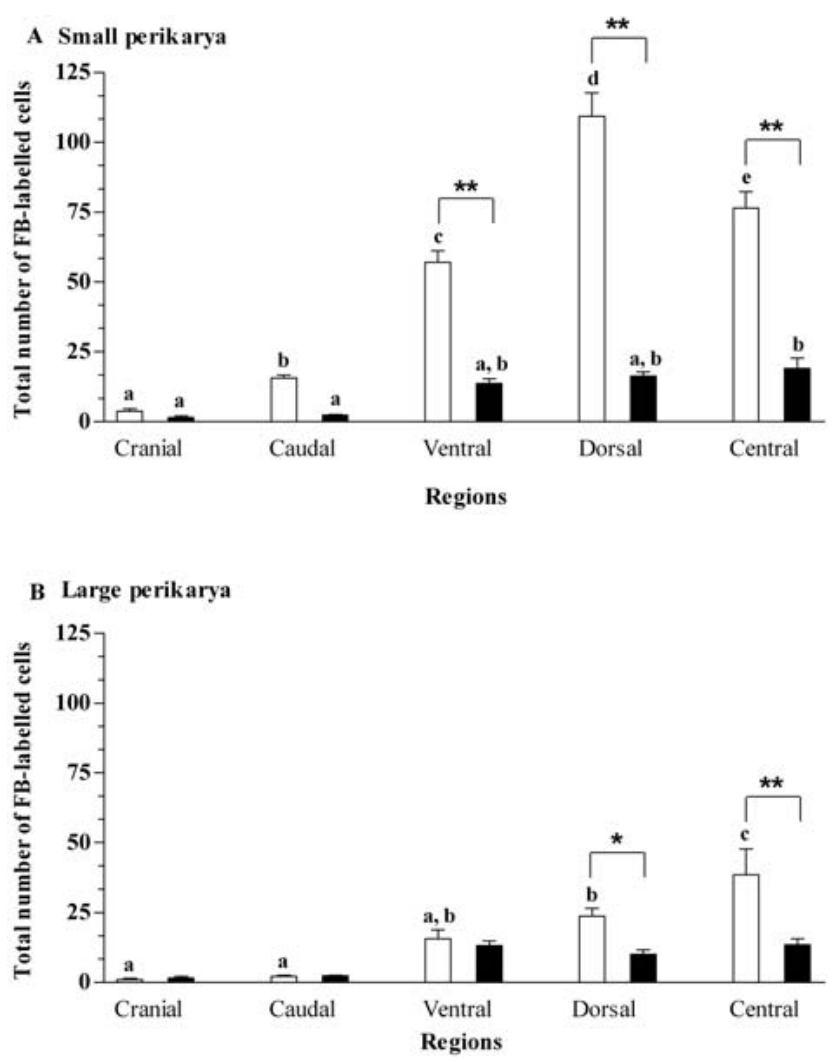

Fig. 1. Mean ( \pm SEM) numbers of small and large ovarian perikarya in particular regions of the CaMGs in the control (open bars) and experimental (solid bars) groups. a, b, c, d, e: different letters indicate differences $(\mathrm{P}<0.05-0.001)$ among the particular regions within the control and experimental groups. $* \mathrm{P}<0.05$, $* * \mathrm{P}<0.001$ : asterisks indicate differences between the groups for the same region.

1B). The numbers of ovarian perikarya populations in particular regions of the CaMGs of both groups are depicted in Fig. 1A and B.

The number of ovarian $\left(F B^{+}\right)$neurons containing $D \beta H, N P Y$, SOM and GAL in the CaMG

$\mathrm{E}_{2}$ injections led to a drop $(\mathrm{P}<0.05)$ in the numbers of $\mathrm{D} \beta \mathrm{H}^{+} /$ $\mathrm{NPY}^{+}$and $\mathrm{D} \beta \mathrm{H}^{+} / \mathrm{NPY}^{-}$small perikarya. Also, this steroid application reduced $(\mathrm{P}<0.05)$ the population of large neurons coded $\mathrm{D} \beta \mathrm{H}^{+} / \mathrm{NPY}^{+}$(Fig. 2A, Fig. 3A-H). In the CaMGs of $\mathrm{E}_{2}$-treated gilts, the numbers of $\mathrm{D} \beta \mathrm{H}^{+} / \mathrm{SOM}^{+}(\mathrm{P}<0.05)$ and $\mathrm{D} \beta \mathrm{H}^{+} / \mathrm{SOM}$ $(\mathrm{P}<0.001)$ small cells were lower than in the control group. Comparative analysis of the control and experimental groups revealed that the numbers of $\mathrm{D} \beta \mathrm{H}^{+} / \mathrm{SOM}^{+}, \mathrm{D} \beta \mathrm{H}^{+} / \mathrm{SOM}^{-}, \mathrm{D} \beta \mathrm{H}^{-} / \mathrm{SOM}^{+}$and $\mathrm{D} \beta \mathrm{H}^{-} / \mathrm{SOM}^{-}$large cells were similar in both groups (Fig. 2B, Fig. 3I-P). Following $\mathrm{E}_{2}$ administration, the number of $\mathrm{D} \beta \mathrm{H}^{+} / \mathrm{GAL}^{-}$ small perikarya was lower $(\mathrm{P}<0.001)$ than that in the control group. In all studied gilts, the numbers of $\mathrm{D} \beta \mathrm{H}^{+} / \mathrm{GAL}^{+}, \mathrm{D} \beta \mathrm{H}^{+} / \mathrm{GAL}^{-}$, $\mathrm{D} \beta \mathrm{H}^{-} / \mathrm{GAL}^{+}$and $\mathrm{D} \beta \mathrm{H}^{-} / \mathrm{GAL}^{-}$large perikarya were similar (Fig. $2 \mathrm{C}$, Fig. 3Q-X). The numbers of ovarian perikarya sets containing $\mathrm{D} \beta \mathrm{H}$ and/or NPY, SOM, GAL as well as not expressing of the above-mentioned substances within the CaMG of the control and $\mathrm{E}_{2}$-injected gilts are presented in Fig. 2A-C.

\section{The number of ovarian $\left(F B^{+}\right)$neurons expressing ERs in the CaMG}

In the CaMGs of the gilts receiving $E_{2}$, the total number of perikarya containing ER subtypes $\alpha$ and/or $\beta$ decreased $(\mathrm{P}<0.001)$ in comparison with the control ganglia (32.04 \pm 6.79 vs. $118.8 \pm$ 15.17 , respectively). This decline refers to the populations of small $(\mathrm{P}<0.001)$ and large $(\mathrm{P}<0.05)$ perikarya expressing ER subtypes $\alpha$ and $\beta$ (Fig. 4 and $5 \mathrm{~A}-\mathrm{P}$ ). The numbers of ovarian perikarya expressing ER subtypes $\alpha$ and/or $\beta$ as well as not expressing these receptors within the ganglia of the control and experimental groups are presented in Fig. 4.

\section{The density of nerve fibers containing $D \beta H, N P Y, S O M$ and GAL in the CaMG}

Compared with the control group, application of $\mathrm{E}_{2}$ resulted in a drop $(\mathrm{P}<0.001)$ of the total number of the intraganglionic nerve fibers containing $\mathrm{D} \beta \mathrm{H}$ and/or NPY $(119.3 \pm 1.85$ vs. $59.1 \pm 2.05$, respectively) and $\mathrm{D} \beta \mathrm{H}$ and/or GAL $(134.7 \pm 2.18$ vs. $43.3 \pm 4.8$, respectively). The populations of fibers containing $\mathrm{D} \beta \mathrm{H}$ and/or SOM differed insignificantly in the experimental and control groups $\left(70.02 \pm 1.52\right.$ vs. $62.1 \pm 2.88$, respectively). $\mathrm{E}_{2}$ treatment reduced $(\mathrm{P}<0.05-0.001)$, as compared with the control group, the numbers of several types of nerve fibers, including $\mathrm{D} \beta \mathrm{H}^{+} / \mathrm{NPY}^{+}$ (7.6 \pm 1.45 vs. $11.67 \pm 1.2$, respectively), $\mathrm{D} \beta \mathrm{H}^{+} / \mathrm{NPY}^{-}(28.03 \pm 1.5$ vs. $37.33 \pm 1.7$, respectively), $\mathrm{D} \beta \mathrm{H}^{-} / \mathrm{NPY}^{+}(23.3 \pm 2.01$ vs. $70.3 \pm$ 2.4 , respectively), $\mathrm{D} \beta \mathrm{H}^{+} / \mathrm{GAL}^{+}(6.33 \pm 1.45$ vs. $11.6 \pm 1.2$, respectively), $\mathrm{D} \beta \mathrm{H}^{+} / \mathrm{GAL}^{-}(22.7 \pm 1.8$ vs. $36.6 \pm 1.85$, respectively) and $\mathrm{D} \beta \mathrm{H}^{-} / \mathrm{GAL}^{+}(13.3 \pm 2.3$ vs. $86.3 \pm 1.45$, respectively). The population of $\mathrm{D} \beta \mathrm{H}^{+} / \mathrm{SOM}^{-}$fibers in the experimental group was found to be higher $(\mathrm{P}<0.01)$ than that in the control group $(33.67 \pm 1.2$ vs. $23.6 \pm 2.02$, respectively; Fig. $6 \mathrm{~A}-\mathrm{L}$ ).

\section{Discussion}

The present study shows, for the first time, that long-term $\mathrm{E}_{2}$ treatment of adult gilts results in a decreased number of CaMG neurons projecting to the ovary. Moreover, reduction of both ovarian noradrenergic and ER-positive perikarya as well as the density of the nerve fibers containing $\mathrm{D} \beta \mathrm{H}$ and/or NPY and $\mathrm{D} \beta \mathrm{H}$ and/or GAL was observed.

We revealed that in $\mathrm{E}_{2}$-injected gilts the total number of ovarian postganglionic neurons in the CaMG was reduced. A similar phenomenon was observed previously in the celiac ganglion projecting to the ovary in rats after prenatal diethylstilbestrol exposure [15]. Repeated administration of estradiol benzoate in female rats also decreased the survival of the hippocampal cells [36]. In turn, Chàvez-Genaro et al. [37] described a reduction of the neuronal soma size during late pregnancy and parallel degeneration of intrauterine sympathetic nerves when the level of $E_{2}$ increased. As demonstrated here, the loss of the ovarian perikarya in the CaMGs of $\mathrm{E}_{2}$-injected gilts may be the consequence of long-term enhancement of the $E_{2}$ level. Although the mechanism for this situation is unclear, we speculate that the $\mathrm{E}_{2}$ level increase might be accompa- 

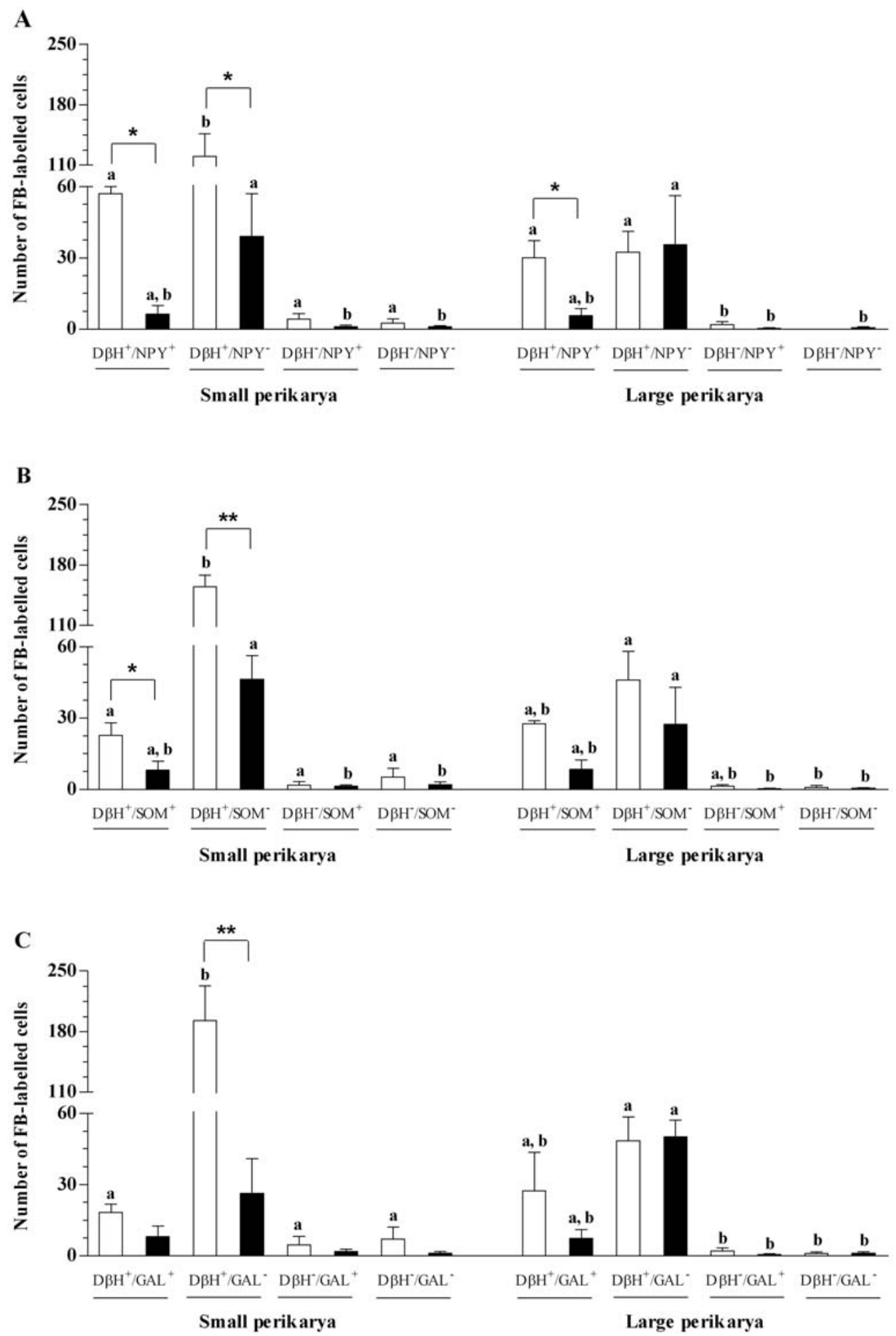

Fig. 2. Mean ( \pm SEM) numbers of small and large ovarian perikarya immunoreactive to $\mathrm{D} \beta \mathrm{H}$ and/or NPY (A), D $\beta \mathrm{H}$ and/or SOM (B) and D $\beta \mathrm{H}$ and/or GAL (C) as well as immunonegative to the above- mentioned substances in the CaMGs of the control (open bars) and experimental (solid bars) groups. a, b: different letters indicate differences $(\mathrm{P}<0.05-0.001)$ among the particular neuronal populations within the control and experimental groups. $* \mathrm{P}<0.05,{ }^{*} \mathrm{P}<0.001$ : asterisks indicate differences between the groups for the same neuronal population. 

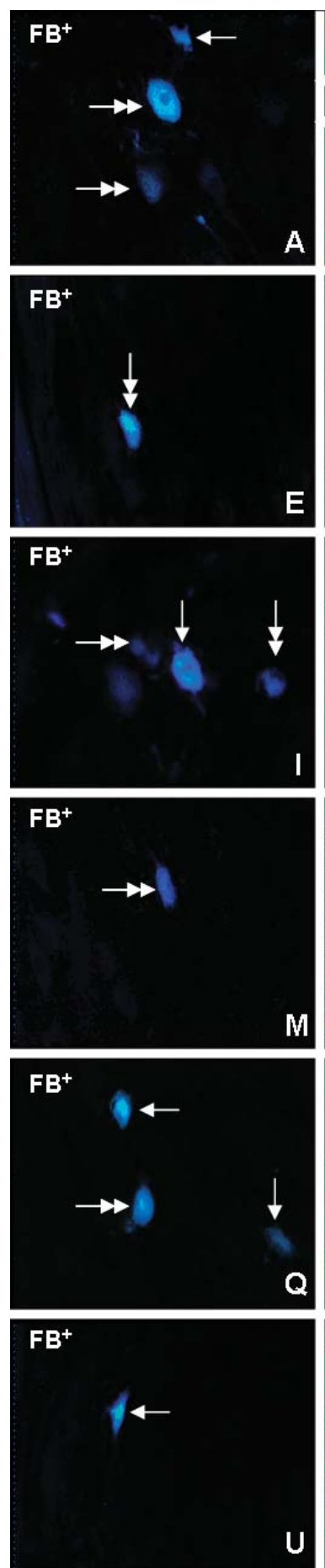
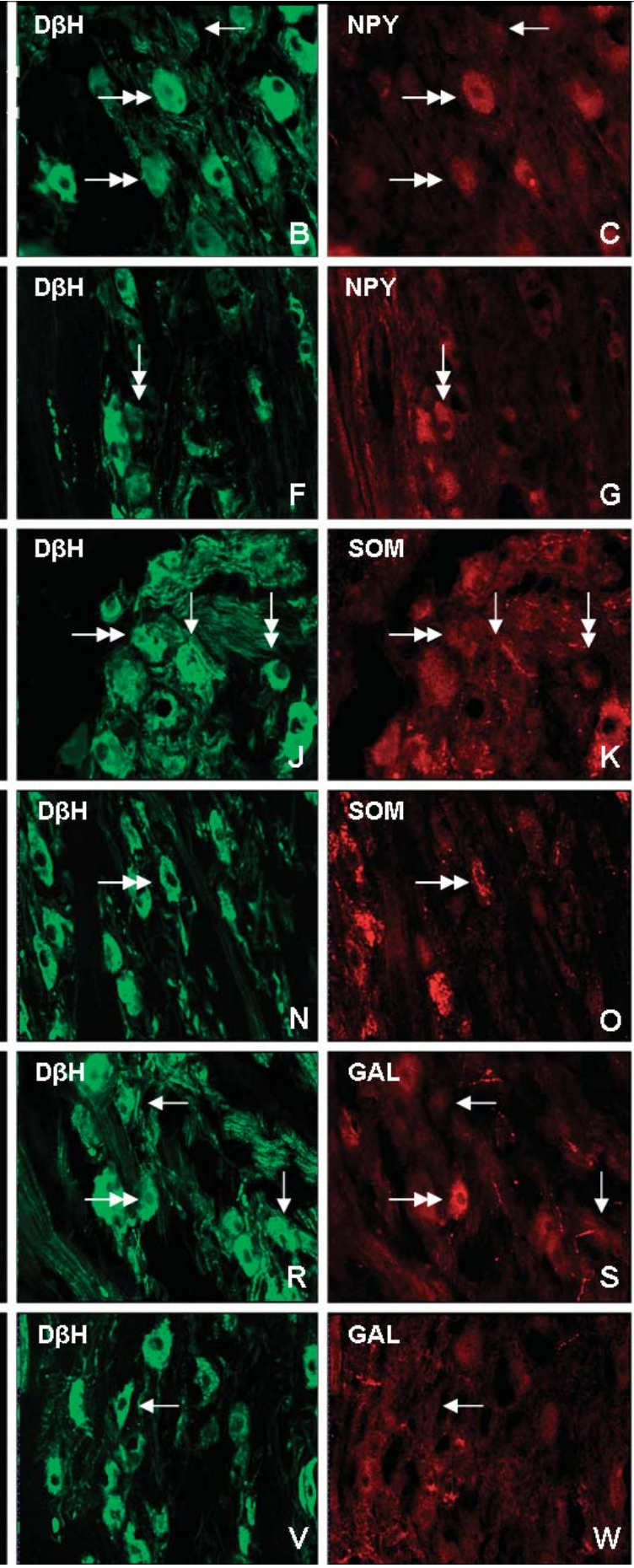
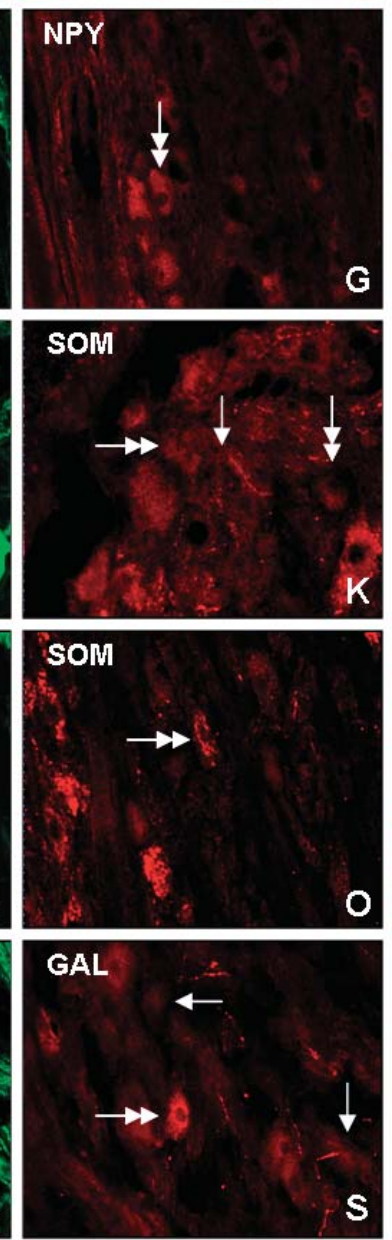

\section{GAL}

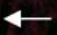

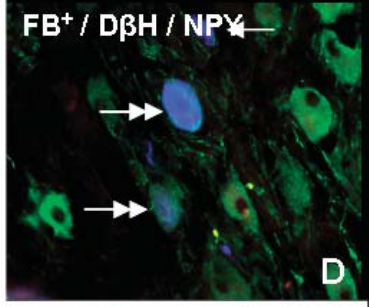
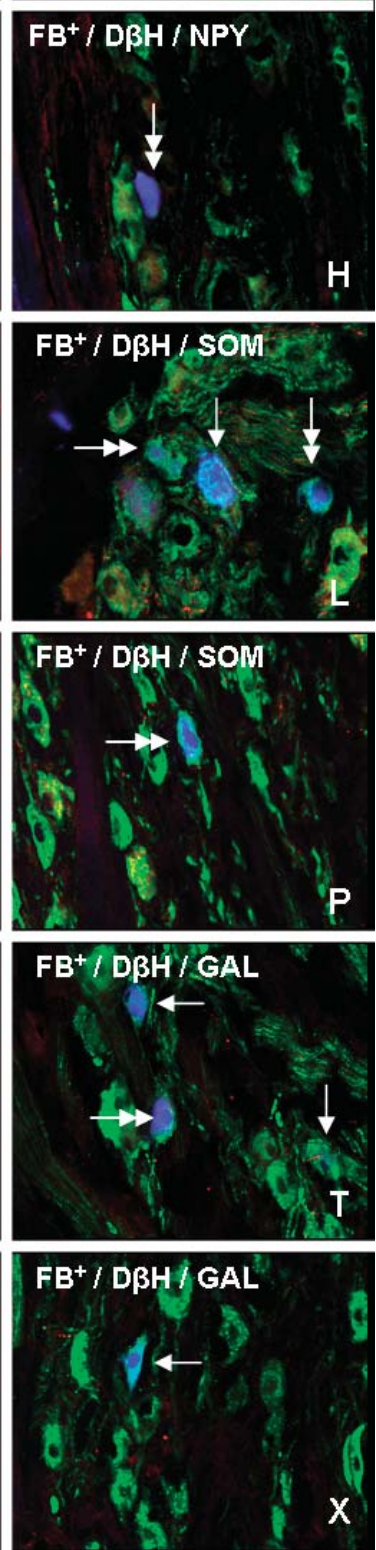

Fig. 3. Fluorescent micrographs showing $\mathrm{D} \beta \mathrm{H}-(\mathrm{B}, \mathrm{F}, \mathrm{J}, \mathrm{N}, \mathrm{R}, \mathrm{V})$, NPY- $(\mathrm{C}, \mathrm{G})$, SOM- $(\mathrm{K}, \mathrm{O})$ and GAL- $(\mathrm{S}, \mathrm{W})$ immunoreactivity in the CaMGs of the control (A-D; I-L; Q-T) and $\mathrm{E}_{2}$-treated (E-H; M-P; U-X) gilts after injections of FB into the ovaries. The double arrows indicate an FB-positive ovarian perikaryon containing two examined substances. The arrow shows an FB-positive ovarian perikaryon containing one of the two examined substances. The photographs D, H, L, P, T and X were created by digital superimposition of three color channels, FB-positive (blue), D $\beta \mathrm{H}-$ positive (green), and NPY-, SOM- or GAL-positive (red). A-D) In the control ganglion, two small ovarian perikarya immunoreactive to D $\beta \mathrm{H}$ and NPY as well as one perikaryon positive to $\mathrm{D} \beta \mathrm{H}$ but negative to NPY are visible. $\mathrm{E}-\mathrm{H}$ ) Note in the $\mathrm{E}_{2}$-affected CaMG, there is a drop in the number of small perikarya containing $\mathrm{D} \beta \mathrm{H}$ and NPY and a lack of perikarya expressing only $\mathrm{D} \beta \mathrm{H}$. I-L) In the control CaMG there are two small perikarya immunoreactive to $\mathrm{D} \beta \mathrm{H}$ and $\mathrm{SOM}$ as well as one perikaryon positive to $\mathrm{D} \beta \mathrm{H}$ but negative to SOM. M-P) In the CaMG after $\mathrm{E}_{2}$ injections, there is a decrease in the population of small perikarya immunoreactive to $\mathrm{D} \beta \mathrm{H}$ and SOM and a lack of perikarya immunoreactive only to $\mathrm{D} \beta \mathrm{H}$. Q-T) Small perikarya positive to $\mathrm{D} \beta \mathrm{H}$ but negative to GAL and a single perikaryon containing these two substances can be seen in the control CaMG. U-X) A noticeable drop in the number of small perikarya containing only $\mathrm{D} \beta \mathrm{H}$ as well as a lack of perikarya expressing $\mathrm{D} \beta \mathrm{H}$ and GAL can be seen in the $E_{2}$-affected CaMG. $\times 200$. 


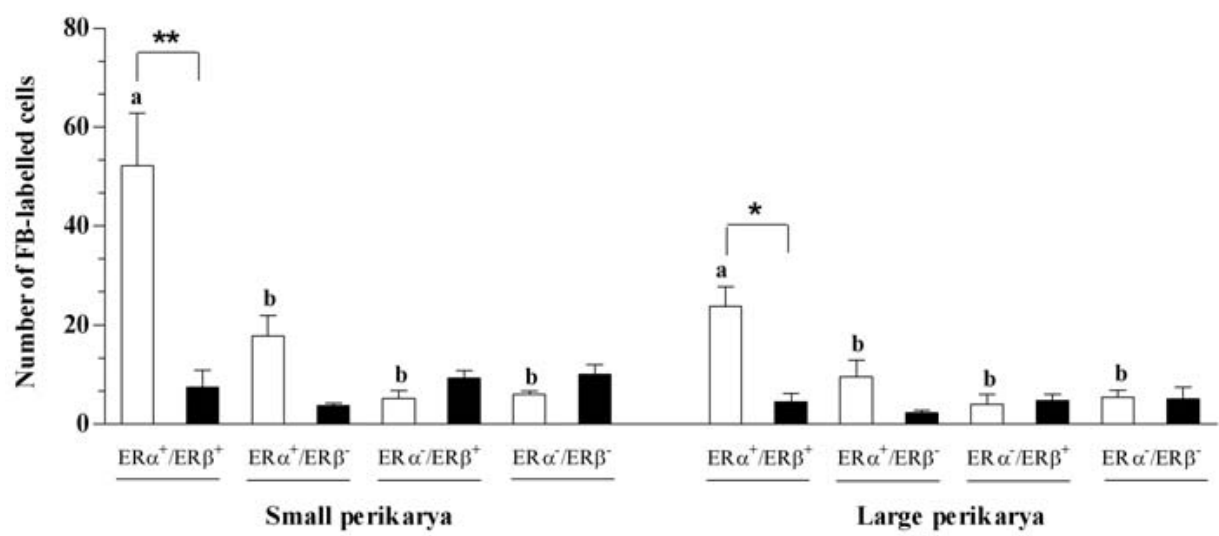

Fig. 4. Mean ( \pm SEM) numbers of small and large ovarian perikarya immunoreactive to ER subtypes $\alpha$ and/or $\beta$ as well as those immunonegative to ERs in the CaMGs of the control (open bars) and experimental (solid bars) groups. a, b: different letters indicate differences $(\mathrm{P}<0.05-0.001)$ among the particular neuronal populations within the control group. ${ }^{*} \mathrm{P}<0.05,{ }^{* *} \mathrm{P}<0.001$ : asterisks indicate differences between the groups for the same neuronal population.
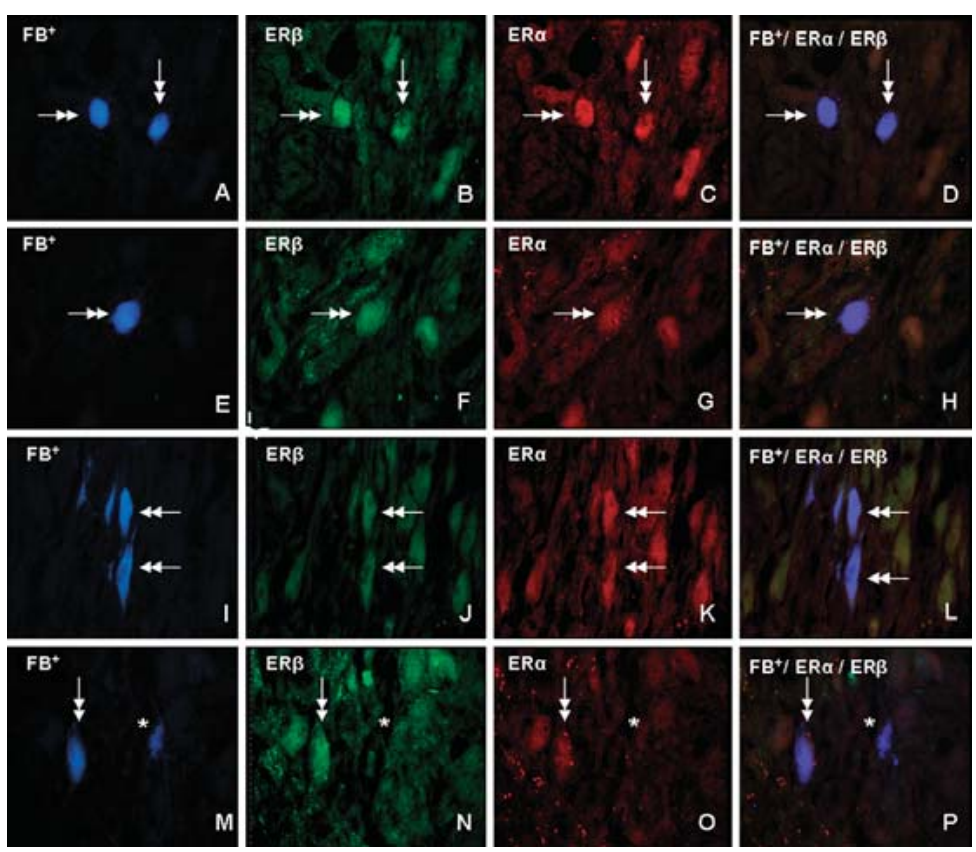
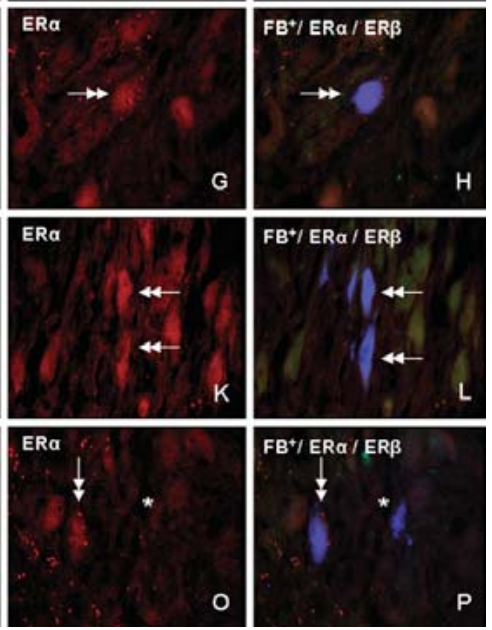
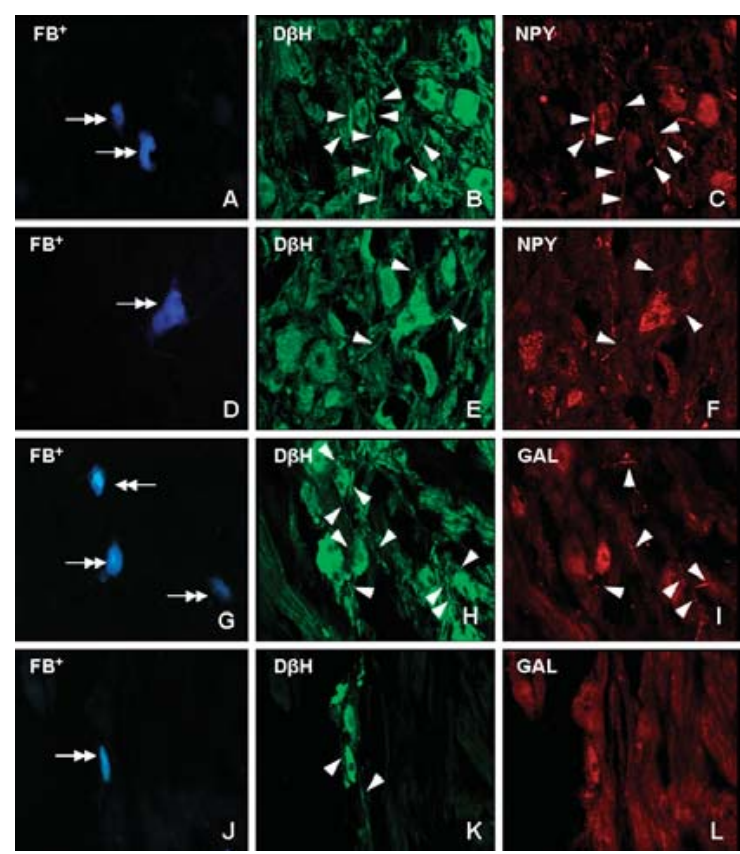

Fig. 5. Fluorescent micrographs showing ER subtypes $\beta(\mathrm{B}, \mathrm{F}, \mathrm{J}, \mathrm{N})$ - and $\alpha(\mathrm{C}, \mathrm{G}, \mathrm{K}$, O)-immunoreactivity in the CaMGs of the control (A-D; I-L) and $\mathrm{E}_{2}$-treated gilts (E-H; M-P) after injections of FB into the ovaries. The double arrows indicate an FB-positive ovarian perikaryon containing two subtypes of ERs. Asterisks indicate an FB-positive perikaryon devoid of ERs. The photographs $\mathrm{D}, \mathrm{H}, \mathrm{L}$ and $\mathrm{P}$ were created by digital superimposition of three color channels, FB-positive (blue), ER $\beta$-positive (green) and ER $\alpha$-positive (red). Two small (A-D) and two large (I-L) perikarya expressing simultaneously ER subtypes $\alpha$ and $\beta$ in the control CaMG. Note that individual small $(\mathrm{E}-\mathrm{H})$ and large $(\mathrm{M}-\mathrm{P})$ perikarya containing ERs are visible in the $\mathrm{E}_{2}$-affected ganglion. $\mathrm{M}-\mathrm{P}$ ) A small ovarian perikaryon negative to ERs was also encountered. $\times 200$.

Fig. 6. Fluorescent micrographs showing the nerve fibers containing $\mathrm{D} \beta \mathrm{H}(\mathrm{B}, \mathrm{F}, \mathrm{H}, \mathrm{K})$ and/or NPY $(\mathrm{C}, \mathrm{F})$ or GAL (I, L) around ovarian perikarya $(\mathrm{A}, \mathrm{D}, \mathrm{G}, \mathrm{J})$ in the CaMGs of the control (A-C; G-I) and $\mathrm{E}_{2}$-treated gilts (D-F; J-L). The double arrows indicate an FB-positive perikaryon. The arrowheads show nerve fibers containing examined substances. Around small perikarya, numerous nerve fibers positive to $\mathrm{D} \beta \mathrm{H}$ and/ or NPY (A-C) as well as $\mathrm{D} \beta \mathrm{H}$ and/or GAL (G-I) can be seen in the control ganglion. In the $\mathrm{E}_{2}$-affected $\mathrm{CaMG}$, there is visible reduction in the number of nerve fibers containing simultaneously $\mathrm{D} \beta \mathrm{H}$ and NPY around a large perikaryon (D-F) and nerve fibers that are $\mathrm{D} \beta \mathrm{H}$-positive and GAL-negative around small perikarya $(\mathrm{J}-\mathrm{L}) . \times 200$. 
nied by downregulated ER expression in the studied perikarya. It is possible that the diminution in the content of the ERs in the studied perikarya could markedly limit the direct $E_{2}$ effects promoting survival of these perikarya, leading to their loss. This can be partly confirmed by the decrease in the number of perikarya positive for ER subtypes $\alpha$ and $\beta$ in the CaMGs of $E_{2}$-injected gilts in the present study. A similar phenomenon was observed previously in the celiac ganglion of rats prenatally exposed to diethylstilbestrol [15] and in the DRG of estradiol benzoate-treated rats [38]. On the fundamental importance of ERs in survival of neurons points out the complete blockade of survival of DRG neurons after application of $E_{2}$ together with ER antagonists [39]. However, it has also been suggested that estrogens may have neuroprotective effects that are not mediated by the ER signaling pathways [40]. On the other hand, the suppression of the number of ovarian perikarya found by us in the $\mathrm{E}_{2}$-treated gilts may also be due to reduced production of NGF, which, as is generally known, plays a crucial role for development and survival of neurons. This supposition is based on the finding that $\mathrm{E}_{2}$ treatment decreased NGF protein content in the sympathetic cervical ganglion of rats [41]. It seems that $E_{2}$ could also contribute to the loss of neurons in the porcine CaMG by desensitization of these cells to NGF, which has previously been observed in rat DRG neurons following a single injection [38] and long-term [22] replacement of estrogen. Also, significant reduction in the number of neurons displaying $\mathrm{p} 75$ protein has been observed at the end of pregnancy, when estrogen levels are increased [42]. Moreover, considering the expression of ERs by neurons in autonomic and sensory areas of the lumbosacral spinal cord that have connections with female reproductive system [43], it is possible that the reduction in the number of postganglionic neurons found in the present study may partly result from changes of the density of ERs receptors on preganglionic neurons in response to $E_{2}$ treatment, which could ultimately affect both the morphology and activity of these cells and consequently disturb the neuronal network function.

It is important to underline that a significant decrease in the number of small but not large ovarian perikarya was observed in the CaMGs of $\mathrm{E}_{2}$-treated gilts in the present study. Simultaneous, reductions in the numbers of small and large perikarya expressing ER subtypes $\alpha$ and $\beta$ were also found in these animals. However, the decreasing effect was more visible in relation to small neurons. The above findings suggest a differential effect of long-term $E_{2}$ administration on the neuronal perikarya depending on their size and ER expression. This supposition is supported by our results showing that the control gilts had a greater number of small ovarian perikarya than large ovarian perikarya expressing ERs in the CaMG as well as by the study of Taleghany et al. [32], which shows that, in the neurons of $\mathrm{L}_{1}-\mathrm{S}_{1}$ DRGs of female and male rats, ER mRNA and protein were localized especially in small neurons.

Our results show the presence of small and large neuronal cells in all studied regions of the CaMGs in both the control and experimental groups. However, following $E_{2}$ application, the numbers of small perikarya decreased in the ventral, dorsal and central regions of the CaMG, while the numbers of large perikarya were lowered only in the dorsal and central regions. The consequence of the reduction in the neuronal populations in the central area as well as along dorsal and ventral domains was substantial diminution of the "ovarian center" observed in the control CaMG, according to earlier findings in immature gilts [3].

We revealed that injections of $E_{2}$ in the gilts decreased the CaMG populations of small perikarya coded $\mathrm{D} \beta \mathrm{H} / \mathrm{NPY}$ (also large perikrya) and $\mathrm{D} \beta \mathrm{H} / \mathrm{SOM}$ as well as the numbers of perikarya immunoreactive to $\mathrm{D} \beta \mathrm{H}$ but immunonegative to NPY, SOM and GAL. Similarly, the number of TH-positive neurons as well as the TH mRNA expression level diminished in the periventricular region of the preoptic area in developing female rats exposed to estrogen [44]. It should be also added that $\mathrm{E}_{2}$ replacement in ovariectomized rats decreased the content of $\mathrm{TH}$ protein in the sympathetic cervical ganglion neurons [41] and the level in $\mathrm{TH}$ mRNA in the nucleus of solitary tract [45]. In contrast, upregulation of TH expression was detected in the rat sympathetic cervical ganglion perikarya during late pregnancy, which is when the estrogen levels are at their highest [46]. While the number of noradrenergic perikarya was downregulated in the present study, no significant changes in the numbers of non-noradrenergic perikarya were found. This is in line with the report of Toji et al. [47] demonstrating that long-term $\mathrm{E}_{2}$ treatment caused no significant alteration in the amount of CGRP- and SP-IR sensory neurons of the urinary bladder in female rats. In turn, other data in the literature show enhancement in NPY and GAL mRNA expression in the trigeminal neurons of mice during proestrus and estrus, which is when $E_{2}$ level is at its highest [48], as well as in the GAL content in lumbosacral sympathetic cells innervating the avian uterine oviduct after $E_{2}$ injection [49]. Also, $E_{2}$ stimulated expression of SP [19], CGRP [20] and PACAP [21] in the DRG neurons projecting to the uterine cervix in adult rats. It is difficult to explain why the numbers of noradrenergic perikarya decreased in the CaMGs of the gilts receiving $\mathrm{E}_{2}$, while the numbers of non-noradrenergic ones were not markedly changed. In spite of the fact that coexpression of ERs and particular substances has yet to be found in the neurons of the sympathetic ganglion, it seems possible that the differential effect of $E_{2}$ on neurons depending on their chemical coding observed by us in the present study could have resulted from a varied density and cellular location of $\operatorname{ER} \alpha$ and/or $\operatorname{ER} \beta$ in the examined populations of neurons $[12,13,16]$.

In the present study, nerve fibers containing $\mathrm{D} \beta \mathrm{H}, \mathrm{NPY}, \mathrm{SOM}$ and/or GAL were present in the CaMGs of both the control and experimental groups. However, the number of nerve fibers immunoractive to $\mathrm{D} \beta \mathrm{H}$ and/or NPY and $\mathrm{D} \beta \mathrm{H}$ and/or GAL in the CaMG of the gilts receiving $\mathrm{E}_{2}$ was markedly lowered, while the population of $\mathrm{D} \beta \mathrm{H}$-and/or SOM-immunoreactive fibers was only slightly changed. There is a lack of data concerning the effect of steroids on the number of intraganglionic nerve fibers. However, it can be assumed that a drop in the density of noradrenergic- and/or peptideimmunoreactive fibers in the $\mathrm{CaMG}$ of $\mathrm{E}_{2}$-injected gilts could partly result from, as revealed in this study, the loss of ovarian perikarya within the ganglion. This assumption is based on earlier data showing that the reduction in the set of the intraovarian sympathetic nerve terminals in rats prenatally exposed to diethylstilbestrol [50] was accompanied by a decrease in the number of sympathetic ovarian perikarya in the celiac ganglion [15]. The changes in the population of nerve fibers within the CaMGs of 
$E_{2}$-treated gilts observed in our study can also result from the effect of $E_{2}$ on perikarya located in other ganglia, such as sympathetic chain ganglia and DRGs. It is known that nerve fibers present in the CaMG originate also from the area of these ganglia, as was shown in gilts [3] and other female species as reviewed by Mawe [51]. Moreover, ERs, as mentioned above, are present in the population of peripheral autonomic and sensory ganglia in female rats $[12,16,17,32]$.

Our data show that long-term $\mathrm{E}_{2}$ treatment of adult gilts results in loss of a specific population of noradrenergic and ERs expressing ovarian neurons in the CaMG. Although further efforts are needed to recognize the mechanism of estrogen influence on these neurons, our findings suggest that an elevated $\mathrm{E}_{2}$ level during pathological states may regulate gonadal function(s) by affecting the CaMG ovary supplying neurons. The present results further support the importance of estrogen as a modulator of neuronal plasticity.

\section{References}

1. Lakomy M, Häppöla $\mathbf{O}$, Majewski M, Wasowicz K. Distribution of some neuropeptides in the porcine inferior mesenteric ganglion. Folia Histochem Cytobiol 1996; 34: 8590

2. Majewski M, Wojtkiewicz J, Gonkowski S, Bossowska A, Sienkiewicz W, Kaleczyc J. Proliferative enteropathy (PE)-induced changes in the expression pattern of $\mathrm{D} \beta \mathrm{H}, \mathrm{NPY}$ and/ or SOM in porcine IMG neurons supplying the descending colon. Pol J Vet Sci 2004; 7 (Suppl 3): 77 (abstract 19).

3. Majewski M, Heym C. The origin of ovarian neuropeptide $\mathrm{Y}(\mathrm{NPY})$-immunoreactive nerve fibres from the inferior mesenteric ganglion in the pig. Cell Tissue Res 1991; 266: 591-596.

4. Majewski M, Heym C. Immunohistochemical localization of calcitonin gene-related peptide and cotransmitters in a subpopulation of post-ganglionic neurons in the porcine inferior mesenteric ganglion. Acta Histochem 1992; 92: 138-146.

5. Czaja K, Kaleczyc J, Pidsudko Z, Franke-Radowiecka A, Lakomy M. Distribution of efferent neurons innervating the oviduct in the pig. Folia Morphol 2001; 60: 243-248.

6. Wasowicz K, Majewski M, Lakomy $\mathbf{M}$. Distribution of neurons innervating the uterus of the pig. J Auton Nerv Syst 1998; 74: 13-22.

7. Balayadi M, Jule Y, Cupo A. Enkephalin-like immunoreactive principal ganglion cells and nerve fibres in the inferior mesenteric ganglion of the cat. Neurosci Lett 1988; 92: 126-131.

8. Alm P, Uvelius B, Ekström J, Holmqvist B, Larsson B, Andersson KE. Nitric oxide synthase-containing neurons in rat parasympathetic, sympathetic and sensory ganglia: a comparative study. Histochem J 1995; 27: 819-831.

9. Elfvin LG, Hökfelt T, Bartfai T, Bedecs K. Immunohistochemical demonstration of galanin-, and galanin message-associated peptide-like immunoreactivities in sympathetic ganglia and adrenal gland of the guinea pig. Microsc Res Tech 1994; 29: 131-142.

10. Kotwica J, Bogacki M, Rekawiecki R. Neural regulation of the bovine corpus luteum. Domest Anim Endocrinol 2002; 23: 299-308.

11. Jana B, Majewski M. Influence of the peripheral nervous system on ovarian function. Med Wet 2007; 63: 1163-1167 (In Polish).

12. Anesetti G, Lombide P, Chávez-Genaro R. Prepubertal estrogen exposure modifies neurotrophin receptor expression in celiac neurons and alters ovarian innervation. Auton Neurosci 2009; 145: 35-43.

13. Zoubina EV, Smith PG. Distributions of estrogen receptors alpha and beta in sympathetic neurons of female rats: enriched expression by uterine innervation. J Neurobiol 2002; 52: 14-23.

14. Zoubina EV, Smith PG. Expression of estrogen receptors alpha and beta by sympathetic ganglion neurons projecting to the proximal urethra of female rats. J Urol 2003; 169: 382-385.

15. Shinohara Y, Matsumoto A, Hayashi S, Mori T. Prenatal exposure to diethylstilbestrol decreases the number of estrogen receptor alpha-containing neurons innervating the ovary in rat celiac ganglion. Neuroscience 2000; 101: 779-783.

16. Papka RE, Srinivasan B, Miller K, Hayashi S. Localization of estrogen receptor protein and estrogen receptor messenger RNA in peripheral autonomic and sensory neurons. Neuroscience 1997; 79: 1153-1163.

17. Papka RE, Storey-Workley M. Estrogen receptor-alpha and -beta coexist in a subpop- ulation of sensory neurons of female rat dorsal root ganglia. Neurosci Lett 2002; 319 71-74.

18. Bennett HL, Gustafsson JA, Keast JR. Estrogen receptor expression in lumbosacral dorsal root ganglion cells innervating the female rat urinary bladder. Auton Neurosci 2003; 105: 90-100

19. Mowa CN, Usip S, Storey-Workley M, Amann R, Papka R. Substance P in the uterine cervix, dorsal root ganglia and spinal cord during pregnancy and the effect of estrogen on SP synthesis. Peptides 2003; 24: 761-771.

20. Mowa CN, Usip S, Collins J, Storey-Workley M, Hargreaves KM, Papka RE. The effects of pregnancy and estrogen on the expression of calcitonin gene-related peptide (CGRP) in the uterine cervix, dorsal root ganglia and spinal cord. Peptides 2003; 24: 1163-1174

21. Papka RE, Workley M, Usip S, Mowa CN, Fahrenkrug J. Expression of pituitary adenylate cyclase activating peptide in the uterine cervix, lumbosacral dorsal root ganglia and spinal cord of rats during pregnancy. Peptides 2006; 27: 743-752.

22. Liuzzi FJ, Scoville SA, Bufton SM. Long-term estrogen replacement coordinately decreases trkA and beta-PPT mRNA levels in dorsal root ganglion neurons. Exp Neurol 1999; 155: 260-267.

23. Hamilton SA, Garverick HA, Keisler DH, Xu ZZ, Loos K, Youngquist RS, Salfen BE. Characterization of ovarian follicular cysts and associated endocrine profiles in dairy cows. Biol Reprod 1995; 53: 890-895.

24. Kengaku K, Tanaka T, Kamomae $\mathbf{H}$. Changes in the peripheral concentrations of inhibin, follicle-stimulating hormone, luteinizing hormone, progesterone and estradiol-17beta during turnover of cystic follicles in dairy cows with spontaneous follicular cysts. J Reprod Dev 2007; 53: 987-993.

25. Yoshioka K, Iwamura S, Kamomae H. Ultrasonic observations on the turnover of ovarian follicular cysts and associated changes of plasma LH, FSH, progesterone and oestradiol-17 beta in cows. Res Vet Sci 1996; 61: 240-244

26. Ebbert W, Elsaesser F, Bostedt $\mathbf{H}$. Cystic degeneration in porcine ovaries-second communication: concentrations of progesterone, estradiol-17 $\beta$, and testosterone in cystic fluid and plasma; interpretation of the results. Reprod Domest Anim 1993; 28: 451-463

27. Kucharski J, Jana B, Zezula-Szpyra A. Effect of the gonadotrophins treatment on morphological alterations in ovary and peripheral plasma concentrations of steroid hormones in gilts. Pol J Vet Sci 2002; 5: 5-15.

28. Tanaka YO, Saida TS, Minami R, Yagi T, Tsunoda H, Yoshikawa H, Minami M. MR findings of the ovarian tumors with hormonal activity, with emphasis on tumors other than sex cord-stromal tumors. Eur J Radiol 2007; 62: 317-327.

29. Slomczyńska M. Xenoestrogens: mechanisms of action and some detection studies. Pol J Vet Sci 2008; 11: 263-269.

30. Swindle MM, Moody DC, Phillips LD (eds.). Swine as Models in Biomedical Research. Ames (IA): Iowa State University Press; 1992: 1-312

31. Hiroi H, Osuga Y, Tarumoto Y, Shimokama T, Yano T, Yokota H, Taketani Y. A case of estrogen-producing Brenner tumor with a stromal component as a potential source for estrogen. Oncology 2002; 63: 201-204.

32. Talaghany N, Sarajari S, DonCarlos LL, Gollapudi L, Oblinger MM. Differential expression of estrogen receptor alpha and beta in rat dorsal root ganglion neurons. J Neurosci Res 1999; 57: 603-615.

33. Neuhuber WL, Sandoz PA, Fryscak T. The central projections of primary afferent neurons of greater splanchnic and intercostal nerves in the rat. A horseradish peroxidase study. Anat Embryol 1986; 174: 123-144.

34. Hotchkiss J, Atkinson LE, Knobil E. Time course of serum estrogen and luteinizing hormone (LH) concentrations during the menstrual cycle of the rhesus monkey. Endocrinology 1971; 89: 177-183.

35. Szafrańska B, Ziecik A, Okrasa S. Primary antisera against selected steroids or proteins and secondary antisera against gamma-globulins-an available tool for studies of reproductive processes. Reprod Biol 2002; 2: 187-204.

36. Barker JM, Galea LA. Repeated estradiol administration alters different aspects of neurogenesis and cell death in the hippocampus of female, but not male, rats. Neuro science 2008; 152: 888-902.

37. Chávez-Genaro R, Lombide $\mathbf{P}$, Anesetti G. A quantitative study of rat uterine sympathetic innervation during pregnancy and post partum. Reprod Fertil Dev 2006; 18: 525531

38. Sohrabji F, Miranda RC, Toran-Allerand CD. Estrogen differentially regulates estrogen and nerve growth factor receptor mRNAs in adult sensory neurons. J Neurosci 1994; 14: 459-471.

39. Patrone C, Andersson S, Korhonen L, Lindholm D. Estrogen receptor-dependent regulation of sensory neuron survival in developing dorsal root ganglion. Proc Natl Acad Sci USA 1999; 96: 10905-10910.

40. Green PS, Bishop J, Simpkins JW. 17 $\alpha$-Estradiol exerts neuroprotective effects on SK-NSH cells. J Neurosci 1997; 17: 511-515.

41. Kaur G, Janik J, Isaacson LG, Callahan P. Estrogen regulation of neutrophin expres- 
sion in sympathetic neurons and vascular targets. Brain Res 2007; 1139: 6-14.

42. Richeri A, Bianchimano P, Mármol NM, Viettro L, Cowen T, Brauer MM. Plasticity in rat uterine sympathetic nerves: the role of TrkA and $p 75$ nerve growth factor receptors. J Anat 2005; 207: 125-134.

43. Papka RE, Hafemeister J, Puder BA, Usip S, Storey-Workley M. Estrogen receptoralpha and neural circuits to the spinal cord during pregnancy. J Neurosci Res 2002; 70: 808-816.

44. Simerly RB. Hormonal control of the development and regulation of tyrosine hydroxylase expression within a sexually dimorphic population of dopaminergic cells in the hypothalamus. Brain Res Mol Brain Res 1989; 6: 297-310.

45. Sabban EL, Maharjan S, Nostramo R, Serova LI. Divergent effects of estradiol on gene expression of catecholamine biosynthetic enzymes. Physiol Behav 2010; 99: 163168.

46. Anglin JC, Brooks VL. Tyrosine hydroxylase and norepinephrine transporter in sympathetic ganglia of female rats vary with reproductive state. Auton Neurosci 2003; 30:
$8-15$.

47. Toji S, Watanabe T, Miyagawa I. Effects of long-term estrogen treatment on micturition behavior and the sensory neurons of the urinary bladder in old female rats. Urol Int 2008; 81: 462-467.

48. Puri V, Cui L, Liverman CS, Roby KF, Klein RM, Welch KM, Berman NE. Ovarian steroids regulate neuropeptides in the trigeminal ganglion. Neuropeptides 2005; 39: 409-417.

50. Shinohara Y, Matsumoto A, Mori T. Effects of prenatal exposure to diethylstilbestrol on the sympathetic nervous system in the rat ovary. Neurosci Lett 1998; 255: 123-126.

49. Ubuka T, Sakamoto H, Li D, Ukena K, Tsutsui K. Developmental changes in galanin in lumbosacral sympathetic ganglionic neurons innervating the avian uterine oviduct and galanin induction by sex steroids. J Endocrinol 2001; 170: 357-368.

51. Mawe GM. Prevertebral, pancreatic and gallbladder ganglia: non-enteric ganglia that are involved in gastrointestinal function. In: McLachlan EM (ed.), Autonomic Ganglia. Luxemburg: Harwood Academic Publishers; 1995: 397-444. 